\title{
The Current Status of Infant Keratoprosthesis
}

\author{
James V Aquavella* \\ University of Rochester Flaum Eye Institute, USA \\ *Corresponding author: James V Aquavella, University of Rochester Flaum Eye Institute, USA
}

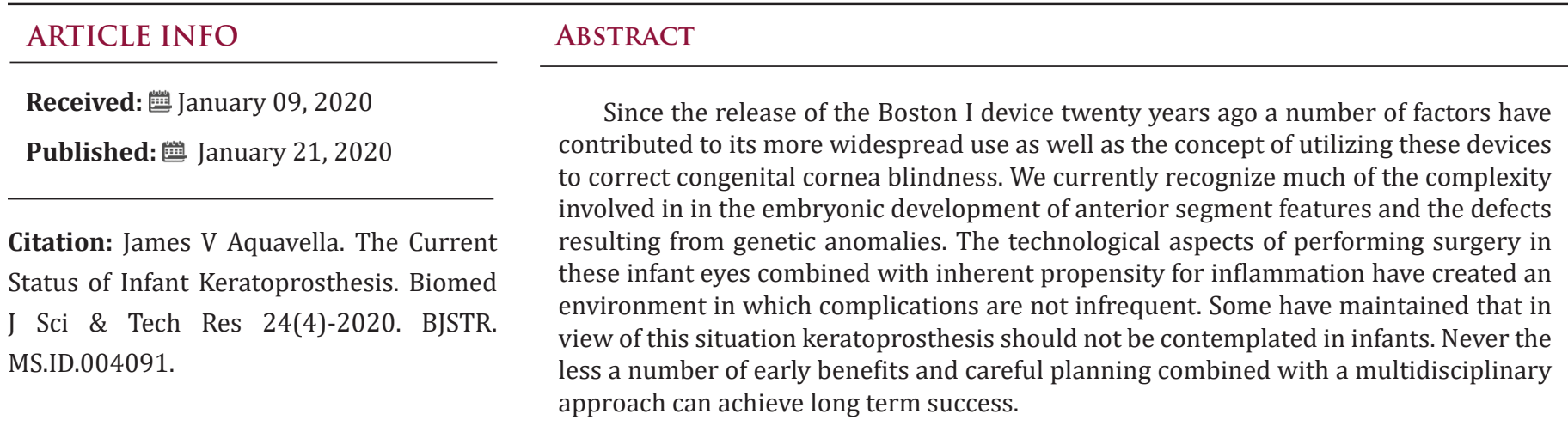

Keywords: Cornea; Keratoprosthesis; Boston I; Congenital Cornea Opacity; Sclerocornea; Cataract

\section{Introduction}

The concepts of pediatric keratoprosthesis (KPro) and more recently infant keratoprosthesis are relatively new. Our first case was performed in 2003. Yet a close inspection reveals that while there are innovations, the general principles utilized are firmly based in historical events. Thus, we recall the team of Cordona, Castroviejo, and Devoe who pioneered the basic KPro techniques in the late 1950's as well as the research conducted by Claes Dohlman culminating in the design of the Boston Type 1 device [1]. If not for the early transactional success associated with this new device, first in end stage disease and then in a variety of less severe conditions, we would not have achieved the degree of success with adults which led to the implantation of these devices to address congenital cornea blindness.

Most cases of congenital cornea blindness until recently were grouped in clinical categories of Peters Anomaly or sclerocornea [2]. However, the work of Kenneth Nischal published in 2015 was important in advancing our understanding of the genesis of these diseases [3-5]. He proposed a clinical surgical classification which included glaucomatous disease associated with the presence of Haabs Strae, infectious conditions such as Herpes simplex, a dystrophic condition to include congenital hereditary endothelial dystrophy (CHED) and posterior polymorphous dystrophy (PPMD), latrogenic produced defects related to amniocentesis and forceps delivery and true developmental defects such as Peters Anomaly and sclerocornea. Primary Congenital Opacity can be further differentiated as follows: Those related to chromosome 20 defects which lead to CHED, PPHD, and some instances of congential glaucoma. Isolated sclerocornea is characterized by anterior displacement of the limbal arcades, a visible anterior chamber and the absence of glaucoma. In complex sclerocornea the eye is microphthalmic with both glaucoma and cataract. While total schlerocomea presents with keratolenicular dysgenesis as well as anterior displacement of the arcades [3].

Secondary congenital cornea opacity has been described as including kerato-lenticular-irido dysgenesis in which the lens fails to separate from the cornea. This occurs during development and is thought to be related to defects in the Fox E3 chromosome. There is a form of mechanical secondary congenital cornea opacity in which the lens fails to form subsequent to its separation from the cornea, called primary aphakia. Other forms of secondary opacity are primary infantile glaucoma in which elevated pressure is the underlying cause of the opacity, aniridia, and Axenfield-Rieger disease. It is clear that determining the specific events underlying these conditions will require a significant amount of further investigation. 
Over the past two decades changes in the design and utilization of the Boston 1 keratoprosthesis have combined to produce the observed significant improvements in device retention and reduction in complications [6]. These advances include the exchange of the diseased cornea with new donor tissue, the fenestration of the back plate, the placement of a bandage contact lens and the use of prophylactic antibiotics $[7,8]$. In addition, there is more attention to the prospect of elevated intraocular pressure and the recognition that glaucomatous disease when associated with keratoprosthesis is an aggressive condition which must be avoided if possible and treated vigorously when suspected. This usually takes the form of implantation of an aqueous shunt prior to prosthesis implantation, during the course of implantation, or following implantation as a secondary procedure.

There are a number of intrinsic and extrinsic impediments which must be considered prior to undertaking the implantation of a keratoprosthesis in infants and young children. The eyeball is small and general anesthesia requires the services of specially trained anesthesiologists. A vigorous immune/inflammatory response is characteristic so that even less invasive procedures such as penetrating keratoplasty are associated with a high rate of postoperative complications. Many of these eyes present with multiple pathology such as cornea opacity, cataract, glaucoma, anterior chamber dysgenesis as well as systemic comorbidity. Posterior segment pathology is not infrequent as well. Follow-up examinations require general anesthesia. And even simple tasks of instilling eye drops can be difficult for the parents to achieve. The recommended bandage contact lens may be difficult to maintain. A partial lateral tarrosaphy may help and wearing of moist chamber goggles will support hydration of the contact and thus assist retention. In the absence of a contact lens the goggles assist in maintaining hydration of the ocular surface and thus in preventing melting of the donor cornea and retraction of the conjunctiva [9].

Our initial efforts always utilized a post-operative antibiotic regimen of $14 \mathrm{mg} / \mathrm{cc}$ Vancomycin in combination with a fourth generation flouroquinalone. Due to the fact that this strength of vancomycin requires that it be a compounded in a hospital pharmacy combined with the prospect for antibiotic resistance current practice has substituted the use of Polytrim in place of the vancomycin. Thus, most have adopted a regimen of fluoroquinalone plus Polytim. Nevertheless, a prophylactic antibiotic regime must be maintained indefinitely. In more than one instance delays in the availability of specifically compounded antibiotics has resulted in endophthalmitis [10]. Recently there has been some thought to the substitution of topical disinfection agents for the antibiotic regimen. We have recently incorporated a technique of covering the prosthesis with a think conjunctival flap [11]. This reduces the incidence of melting of the donor cornea. There are those who feel the procedure should not be utilized in infants in view of the level of postoperative support necessary and the high rate of complications [12]. The fact that a multidisciplinary approach is necessary, involving a number of ophthalmic specialists and support staff, is an impediment to the development of sites capable of providing the necessary resources. The rare occurrences of congenital cornea opacity limit the potential for interested ophthalmic surgeons to gain experience in the required techniques.

Factors favorable to the adoption of the procedure in infants include the almost immediate improvement in vision which is associated with numerous developmental advantages, even if the underlying improvement in vision were to prove to be of limited duration [13]. Thus, the critical importance of parental understanding of the associated difficulties and risks involved $[13,14,15]$. The infant population is noted for a strong immune response which is thought to be associated with the increased risk of postoperative melting and other inflammatory sequelae. In adults with preexisting severe ocular surface disease immunosuppression combined with total closure of a thick conjunctival flap for the first few weeks is thought to be effective. However, immunosuppression of infants is currently viewed as presenting an unacceptable risk. In the final analysis there are multiple genetic, ethical, developmental, and administrative aspects at work which have produced a variety of opinions. All of this aside from the devices technical and surgical aspects which must be considered. Yet we firmly believe in this initiative to provide functional acuity in cases where permanent blindness is the alternative.

\section{References}

1. DeVoe AG (1977) Keratoprosthesis. History, techniques, and indications. Trans Sect Ophthalmol Am Acad Ophthalmol Otolaryngol 83(2): 249251.

2. Harris JK, Rao GN, Aquavella JV, Lohman LE (1948) Keratoprosthesis: technique and instrumentation. Ann Ophthalmol 16(5): 481-484.

3. Nouri M, Terada H, Alfonso EC, Foster CS, Durand ML, et al. (2001) Endophthalmitis after keratoprosthesis: incidence, bacterial causes, and risk factors. Arch Ophthalmol 119(4): 484-489.

4. Trief D, Marquezan MC, Rapuano CJ, Prescott CR (2017) Pediatric corneal transplants. Curr Opin Ophthalmol 28(5): 477-484.

5. World Health Organization Fact Sheet 273.

6. Fung SSM, Jabbour S, Harissi Dagher M, Tan RRG, Hamel P, et al. (2018) Visual Outcomes and Complications of Type I Boston Keratoprosthesis in Children: A Retrospective Multicenter Study and Literature Review. Ophthalmology 125(2): 153-160.

7. Gollamudi SR, Traboulsi EI, Chamon W, Stark WJ, Maumenee IH (1994) Visual outcome after surgery for Peters' anomaly. Ophthalmic Genet 15(1): 31-35.

8. Dohlman CH, Dudenhoefer EJ, Khan BF, Morneault S (2002) Protection of the ocular surface after keratoprosthesis surgery: the role of soft contact lenses. CLAO J 28(2): 72-74.

9. Aquavella J, Wozniak R (2018) Benefits of Multidisciplinary Team Approach to Infant Keratoprosthesis. Int J Ophthal Vision Res 2(1): 008010 .

10. Ramchandran RS, Diloreto DA, Chung MM, Kleinman DM, Plotnik RP, et al. (2012) Infectious endophthalmitis in adult eyes receiving Boston type I keratoprosthesis. Ophthalmology 119(4): 674-681.

11. Nass R, Frank Y (2010) Cognitive and Behavioral Manifestations of Pediatric Disease. Oxford University Press. 
12. Fung SSM, Jabbour S, Harissi Dagher M, Tan RRG, Hamel P, et al. (2018) Visual Outcomes and Complications of Type I Boston Keratoprosthesis in Children: A Retrospective Multicenter Study and Literature Review. Ophthalmology 125(2): 153-160.

13. Payrau P, Moczar M, Moczar E (1969) Preparation of nonturgescible corneal transplants: initial surgical results. Bull Soc Ophtalmol.

ISSN: 2574-1241

DOI: $10.26717 /$ BJSTR.2020.24.004091

James V Aquavella. Biomed J Sci \& Tech Res

(C) This work is licensed under Creative

Submission Link: https://biomedres.us/submit-manuscript.php
14. Pasqualotto A, Proulx MJ (2012) The role of visual experience for the neural basis of spatial cognition. Neurosci Biobehav Rev 36(4): 11791187.

15. Orzolek Kronner C (2006) The impact of sight loss in social work practice. J Soc Work Disabil Rehabil 6(1-2): 157-177.

$\begin{array}{ll}\text { BIOMEDICAL } & \text { Assets of Publishing with us } \\ \text { RESEARCHES } & \text { - Global archiving of articles } \\ \text { - Immediate, unrestricted online access }\end{array}$

